OPEN ACCESS

Edited by:

Gen-Min Lin

Hualien Armed Forces General

Hospital, Taiwan

Reviewed by:

Rabaa Zaibi,

Tunis El Manar University, Tunisia

Dana Pop,

Iuliu Hațieganu University of Medicine

and Pharmacy, Romania

${ }^{*}$ Correspondence:

Randal J. Thomas

thomas.randa@mayo.edu

Specialty section:

This article was submitted to Cardiovascular Epidemiology and

Prevention,

a section of the journal

Frontiers in Cardiovascular Medicine

Received: 30 March 2021

Accepted: 31 May 2021

Published: 28 June 2021

Citation:

Supervia M, Medina-Inojosa JR, Pérez-Terzic CM, Sharma S, Goel K,

Vickers Douglas K, Salz K and

Thomas RJ (2021) Impact of

Musculoskeletal Limitations on

Cardiac Rehabilitation Participation.

Front. Cardiovasc. Med. 8:688483.

doi: 10.3389/fcvm.2021.688483

\section{Impact of Musculoskeletal Limitations on Cardiac Rehabilitation Participation}

\author{
Marta Supervia ${ }^{1,2}$, Jose R. Medina-Inojosa ${ }^{2}$, Carmen M. Pérez-Terzic ${ }^{2,3}$, Saurabh Sharma ${ }^{4}$, \\ Kashish Goel ${ }^{5}$, Kristin Vickers Douglas ${ }^{6}$, Karen Salz $^{2}$ and Randal J. Thomas ${ }^{2 *}$ \\ ${ }^{1}$ Gregorio Marañón General University Hospital, Gregorio Marañón Health Research Institute, Madrid, Spain, \\ ${ }^{2}$ Cardiovascular Rehabilitation Program, Department of Cardiovascular Diseases, Mayo Clinic, Rochester, MN, \\ United States, ${ }^{3}$ Department of Physical Medicine and Rehabilitation, Mayo Clinic, Rochester, MN, United States, ${ }^{4}$ Guthrie \\ Robert Packer Hospital, Sayre, PA, United States, ${ }^{5}$ Department of Cardiovascular Diseases, Vanderbilt University Medical \\ Center, Nashville, TN, United States, ${ }^{6}$ Department of Psychiatry and Psychology, Mayo Clinic, Rochester, MN, United States
}

Background: To help clarify a potential barrier to cardiac rehabilitation (CR) participation we sought to examine the association between musculoskeletal limitations (MSLs) and CR enrollment and participation.

Methods: Consecutive CR eligible individuals hospitalized for a cardiac event (myocardial infarction, percutaneous coronary intervention, and/or coronary artery bypass graft) between the months of November 2007 and May 2008, were asked to complete a mailed survey within 2 weeks after hospital discharge, assessing demographic factors, Patient Health Questionnaire (PHQ-9), participation in CR and MSLs through a validated MSLs screening tool. CR enrollment rates were compared between patients with and without MSLs.

Results: Three hundred and twenty-one (37\%) of patients contacted responded to our survey, including 228 males (71\%), with a mean age $68 \pm 10.8$ years, of whom $98 \%$ were Caucasian. Eighty-two percent of responders reported a musculoskeletal disorder at the time of hospital discharge. Arthritis was the most frequent diagnosis (45\%). Muscle or joint pain sufficient to limit the ability to do moderate exercise was reported in $52 \%$ of the respondents. Problems with balance affected 37\%, of whom $45 \%$ reported a fall within the previous year. No significant difference in CR enrollment was observed in respondents with and without MSLs [OR $=0.98,95 \% \mathrm{Cl}(0.88-1.09), p=0.750]$. Similar results were found when severity and number of MSLs were taken into account. However, we found that when compared to those without MSLs, the presence of MSLs was associated with lower CR participation (OR $=0.80,95 \%, \mathrm{Cl}: 0.65-0.97, p=0.0252$ ).

Conclusion: Despite a high prevalence of MSLs among CR-eligible patients, we found no association between MSLs and CR enrollment. However, patients with MSLs attended significantly fewer CR sessions as compared to patients without them. CR programs should consider providing additional support and interventions to patients with MSLs in order to optimize their adherence to prescribed CR sessions.

Keywords: cardiovascular rehabilitation, patient participation, musculoskeletal diseases, musculoskeletal pain, cardiac rehabilitation, physiatrist 


\section{INTRODUCTION}

Cardiac rehabilitation (CR) is a cost-effective and integral component of the continuum of care for cardiac patients $(1,2)$ that improves functional status and psychological health (1), and reduces morbidity, re-hospitalization and mortality rates (3). CR that was later established in clinical practice guidelines as a Class I recommendation $(4,5)$ for patients with a wide range of cardiac conditions. However, despite these facts, CR is underutilized 2, particularly in patients with significant comorbidities $(6,7)$. A number of potential factors have been identified as barriers to CR participation, including patient-, medical-, and healthcare system-level factors.

Musculoskeletal limitations (MSLs) are common in the general population and particularly prevalent in patients with coronary artery disease $(8,9)$. They are a major source of disability, immobility and dependence (10-13), yet little is known about their potential impact on CR participation.

Since it is unknown if MSLs prevent patients from enrolling in a CR program, we aim to examine (1) the prevalence of MSLs in patients referred to CR and (2) explore its possible roles as a barrier to patient enrollment and completion in phase II CR.

We sought to help clarify whether or not MSLs serve as a barrier to CR participation by assessing, in a consecutive sample of hospitalized patients, the association between MSLs and CR enrollment, as well as between MSLs and CR participation.

\section{MATERIALS AND METHODS}

Consecutive individuals hospitalized for a CR-eligible cardiac event [myocardial infarction (MI), percutaneous coronary intervention (PCI), and/or coronary artery bypass graft (CABG) surgery] between November 2007 and May 2008 were mailed a study packet containing a consent form and survey within 2 weeks of hospital discharge.

Individuals were identified through daily census records of the Mayo Clinic hospitals in Rochester, Minnesota, by the inpatient Cardiovascular Health Clinic team. Patients were included in the study if they were $>18$ years of age and had one or more of the qualifying diagnoses (MI, PCI, and/or CABG). Patients who were unable to read and write in English were excluded. Individuals who met the study's entry criteria were sent a study packet containing a written consent form, as well as a detailed description of the study, and the study survey tool. Individuals who agreed to enter the study were instructed to fill out the consent form and the study survey. Persons who did not agree to enter the study were instructed to fill out the consent form indicating that they did not wish to participate in the study.

Self-report items were used to assess participants' demographic information (age, gender, education level, marital status, ethnicity, employment status), self-reported CR recommendation by health care provider, depressive symptoms, presence of comorbidities (Charlson index), perceived health (5point scale ranging from "poor" to "excellent"), and presence of MSLs as documented by a validated Musculoskeletal Limitations Screening questionnaire. Enrollment and number of sessions attended in CR were obtained from the medical records.
Depressive symptoms were assessed with the Patient Health Questionnaire (PHQ-9), a self-report measure that captures both cognitive and physical symptoms of clinical depression with a higher score indicating more depressive symptoms. Scores range from 0 to 27, with higher scores indicating greater depressive symptom severity. Scores of 10 and higher indicate moderate to severe depressive symptom severity (14).

\section{Identification of Musculoskeletal Limitation}

We used a 7 item screening tool that was developed in the Cardiovascular Health Clinic to identify MSLs that may impact a person's quality of life and their ability to exercise or participate in other related cardiovascular disease prevention activities. Seven questions in the screening tool asked about the (1) intensity of the muscle and joint pain on a scale of (1-10); (2) duration of pain; (3) effect of existing pain on the ability to perform moderate exercises; (4) pain relief achieved by medication usage; (5) effect of balance problems on the ability to perform moderate exercises; (6) presence of specific musculoskeletal diagnoses (arthritis, spinal stenosis, herniated vertebral disc, etc.); and (7) history of any of the following: a fall in the previous year, an amputation of a limb/finger/toe, joint replacement surgery, any joint surgery (including back) and stroke (Supplementary Table 1). Testretest validity of the musculoskeletal screening tool was assessed and showed high correlation (see Supplementary Table 1 and Table 1). This study was approved by Mayo Clinic Institutional Review Board.

\section{Statistical Analysis}

We assessed study variables as frequencies and percentages, mean values and standard deviations (SD) or median and interquartile ranges, depending on the distribution of the variables. We calculated intra-class correlation indices and Kappa statistic to test-retest validity of the musculoskeletal screening tool.

Multivariate logistic regression analysis was used to assess independent predictors associated with CR enrollment adjusting for age, gender, smoking status, PHQ-9 score, level of education, musculoskeletal comorbidities, and the Charlson comorbidity index (Table 4). Findings were summarized using odds ratios (OR) and 95\% confidence intervals. In all cases, two-tailed $p$ values $\leq 0.05$ were used to denote statistical significance $\alpha$ level of 0.05. All analyses were completed using SAS ${ }^{\circledR} 9.3$ (SAS Institute Inc., Cary, NC).

\section{RESULTS}

\section{Response Rate and Participants Characteristics}

Out of 862 patients who were sent study packets, 321 (37\%) consented to participate and returned the study survey.

The sample composition was predominately male (71\%), white $(98 \%)$, married $(75.4 \%)$, with a relatively high level of education (13.9 years \pm 3.5 ), and with a mean age of $68 \pm 10.8$ years. The mean PHQ9 score was $5.2 \pm 4.5$, with women having higher scores than men $(6.3 \pm 4.3$ vs. $4.7 \pm 4.6, p=0.008)$. Eighty-six percent of the patients 
TABLE 1 | Demographics.

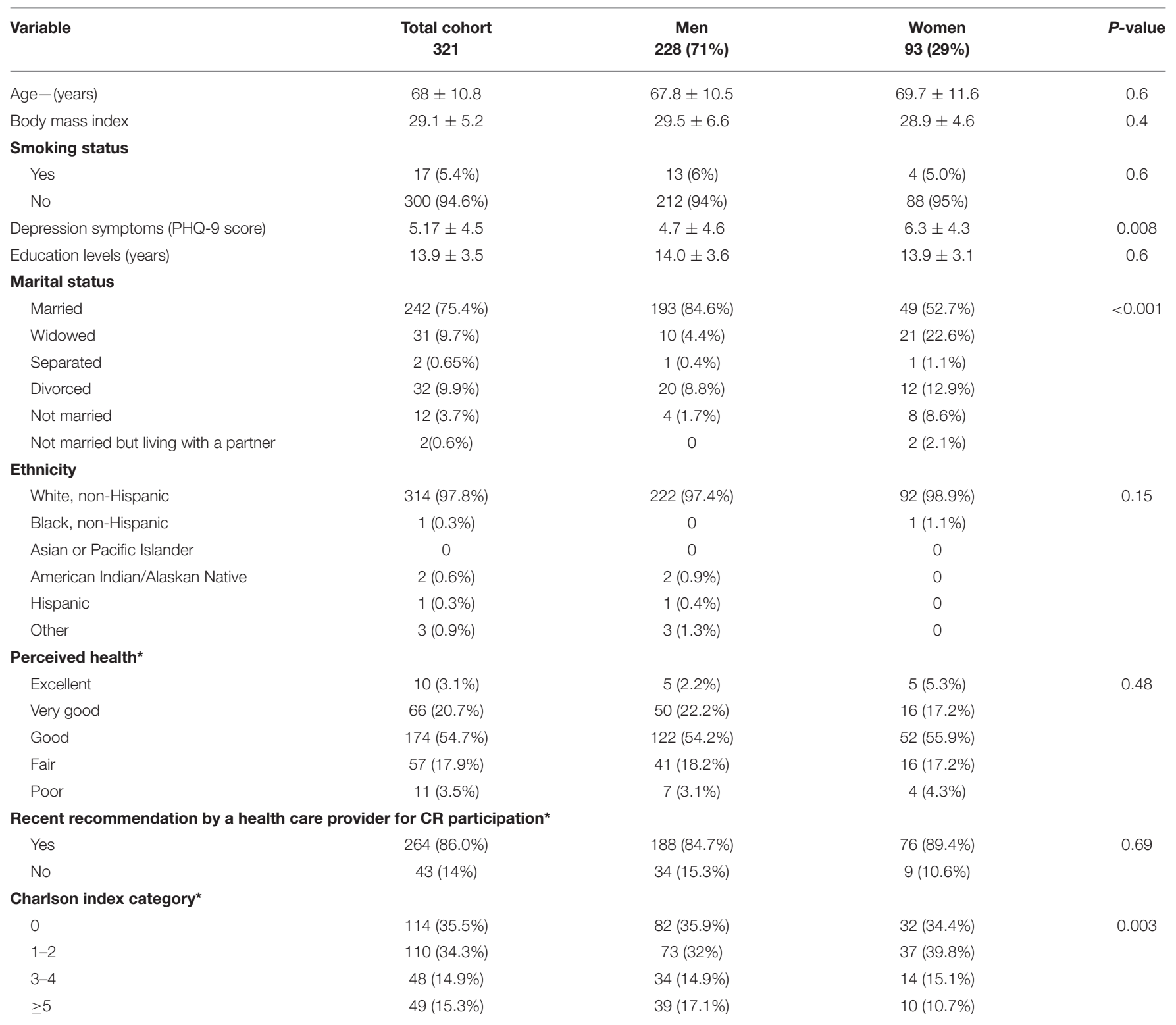

$S D$, standard deviation.

${ }^{\star}$ Based on data available.

reported a recent recommendation by a health care provider to participate in CR. Almost $80 \%$ of patients perceived their health status to be "good" or better, and over $70 \%$ were classified in the Charlson Index categories 0-2 (Table 1). Enrollment in CR was reported in 54\% (56\% of men and 53\% of women).

\section{Prevalence of Musculoskeletal Limitations}

Musculoskeletal limitations including any type of chronic muscular or joint pain of varying intensity and duration, were present in $82 \%$ of respondents ( $83.3 \%$ male, $85.2 \%$ female), with over $54.2 \%$ noting that the MSL had been present for at least 1 year. Sixty percent of patients reported that MSL-related pain limited their ability to perform moderate exercises such as walking, biking or swimming. Balance problems were reported by $37 \%$ of respondents $(32.9 \%$ in men and $47.1 \%$ in women, $p$ $=0.01$ ), while $53 \%$ reported a fall in the previous year. Gender differences were found in joint swelling (8.3\% in men vs. $19.3 \%$ in women, $p=0.007)$ and spinal stenosis $(3.1 \%$ in men and $14 \%$ in women, $p=0.0005$ ) too (Table 2). Fifty-five percent of respondents reported having at least one MSL-related diagnosis including: arthritis in the joints (45.2\%), joint swelling (17\%), inflammatory arthritis (13\%), and previous joint surgery (20\%) (see Table 2). Women were more frequently diagnosed with any or all of the possible MSL-related diagnoses (65.59\% women vs. 50.88 men, $p=0.01$ ). 
TABLE 2 | Patient distribution according to musculoskeletal limitations screening questionnaire.

\begin{tabular}{|c|c|c|c|c|}
\hline & $N(321)$ & Men (228) & Women (93) & $P$-value \\
\hline Intensity of muscle/joint pain & 302 & 214 & 88 & \\
\hline No pain & $51(16.9 \%)$ & 38 (17.7\%) & $13(14.8 \%)$ & 0.14 \\
\hline Pain rated $1-5$ & 175 (58.3\%) & 129 (60.3\%) & $46(52.3 \%)$ & \\
\hline Pain rated 6-10 & 76 (23.7\%) & 47 (22\%) & 29 (32.9\%) & \\
\hline Duration of joint pain & 310 & 221 & 89 & \\
\hline No pain & $83(26.7 \%)$ & $63(28.5 \%)$ & $20(22.5 \%)$ & 0.16 \\
\hline$<1$ month & $21(6.8 \%)$ & $17(7.7 \%)$ & $4(4.5 \%)$ & \\
\hline 1 month-1 year & 38 (12.2\%) & 29 (13.1\%) & $9(10.1 \%)$ & \\
\hline$>1$ year & 168 (54.2\%) & 112 (50.7\%) & $56(62.9 \%)$ & \\
\hline Effect of pain on ability to perform moderate exercises (walking, biking, or swimming) & 310 & 220 & 90 & \\
\hline No limitation & $125(40.3 \%)$ & $100(45.4 \%)$ & $25(27.8 \%)$ & 0.01 \\
\hline Slight to moderate limitation & $161(52 \%)$ & $105(47.7 \%)$ & $56(62.2 \%)$ & \\
\hline Severe limitation & $24(7.7 \%)$ & $15(6.8 \%)$ & $9(10 \%)$ & \\
\hline Pain relief with medications & 278 & 198 & 80 & \\
\hline No pain medication & $138(49.2 \%)$ & $106(53.5 \%)$ & $32(40 \%)$ & 0.07 \\
\hline Pain medications present & $140(50.4 \%)$ & $92(46.5 \%)$ & $48(60 \%)$ & \\
\hline No pain relief & $10(3.6 \%)$ & $8(4 \%)$ & $2(2 \%)$ & \\
\hline Slight to near total pain relief & $130(46.8 \%)$ & $84(42.4 \%)$ & $46(57.5 \%)$ & \\
\hline Balance problems affecting ability to perform moderate exercise & 309 & 222 & 87 & \\
\hline No balance problems & $195(63.1 \%)$ & $149(67.1 \%)$ & $46(52.9 \%)$ & 0.01 \\
\hline Balance problems present & $114(36.9 \%)$ & $73(32.9 \%)$ & $41(47.1 \%)$ & \\
\hline No limitation & $41(13.3 \%)$ & $27(12.2 \%)$ & $14(16.1 \%)$ & \\
\hline Slight to moderate limitation & $65(21 \%)$ & $43(19.4 \%)$ & $22(25.3)$ & \\
\hline Severe limitation & $8(2.6 \%)$ & $3(1.3 \%)$ & $5(5.7 \%)$ & \\
\hline Patients who were told by a healthcare professional that they have the following & 177 & 116 & 61 & \\
\hline Arthritis in the joints & $145(45.2 \%)$ & $92(40.3 \%)$ & $53(57 \%)$ & 0.006 \\
\hline Herniated disk in the back/neck & $45(14 \%)$ & $29(12.7 \%)$ & $16(17.2 \%)$ & 0.3 \\
\hline Inflammatory arthritis & $24(7.5 \%)$ & $14(6.1 \%)$ & 10(10.7\%) & 0.1 \\
\hline Osteoporosis & $28(8.7 \%)$ & $5(2.2 \%)$ & $23(24.7 \%)$ & $<0.001$ \\
\hline Spinal stenosis & $20(6.2 \%)$ & $7(3.1 \%)$ & $13(14 \%)$ & 0.0005 \\
\hline Vertebral or spinal fracture & $11(3.4 \%)$ & $7(3.1 \%)$ & $4(4.3 \%)$ & 0.5 \\
\hline Joint swelling & $37(11.5 \%)$ & $19(8.3 \%)$ & $18(19.3 \%)$ & 0.007 \\
\hline Neurological problem other than stroke & $6(1.9 \%)$ & $4(1.7 \%)$ & $2(2.1 \%)$ & 0.8 \\
\hline Patients with following history & $121(37.7 \%)$ & $87(38.2 \%)$ & 34 (36.6\%) & 0.7 \\
\hline Falls in past year & $69(21.5 \%)$ & $52(22.8 \%)$ & $17(18.3 \%)$ & 0.3 \\
\hline Amputation of a limb/finger/toe & $6(1.8 \%)$ & $5(2.2 \%)$ & $1(1.1 \%)$ & 0.4 \\
\hline Joint replacement surgery & $29(9 \%)$ & 19 (8.3\%) & $10(10.7 \%)$ & 0.4 \\
\hline Joint surgery (including back) & $32(10 \%)$ & $22(9.6 \%)$ & $10(10.7 \%)$ & 0.7 \\
\hline Stroke & $21(6.5 \%)$ & $13(5.7 \%)$ & $8(8.6 \%)$ & 0.3 \\
\hline
\end{tabular}

\section{Predictors of CR Enrollment}

Univariate predictors of CR enrollment are shown in Table 3 and include: age, gender, smoking current status, PHQ-9, education level, Charlson index and MSLs screen. Respondents with MSLs were no more likely to enroll in CR than those without MSLs (77.38 vs. $77.78 \%, p=0.9$ ). This was not different when stratifying the analysis by gender, for males $p=0.5$, for females $p=0.6$.

Multivariate analysis revealed that a recommendation by a health care provider for the patient to participate in CR was the strongest independent predictor of CR enrollment (HR 3.62, 95\%
CI: $1.55-8.47, p=0.002)$. In addition, a lower PHQ9 score was independently predictive of $\mathrm{CR}$ enrollment compared to those with a higher score (HR 0.93, 95\% CI: 0.87-0.99, $p=0.016$ ). Younger age also predicted CR enrollment (HR 0.96, 95\% CI: $0.94-0.99, p=0.005$ ) (see Table 4). Presence of at least one MSL was not predictive of $\mathrm{CR}$ enrollment, and this finding did not change even after consideration of the number and severity of MSLs $[\mathrm{OR}=0.97,95 \%$ CI (0.57-1.56), $P=0.9$-any MSL vs. no MSL]. Respondents with severe MSLs were no more likely to enroll in CR than were respondents with mild and no MSLs (HR 0.98, 95\% CI: $0.88-1.09 p=0.75$ ). 
TABLE 3 | Predictors of CR participation.

\begin{tabular}{lccc}
\hline Parameter & Odds ratio & $\begin{array}{c}\mathbf{9 5 \%} \mathbf{C l} \\
\text { lower-upper }\end{array}$ & $\boldsymbol{P}$-value \\
\hline Age & 0.97 & $0.95-0.99$ & 0.04 \\
Male & 0.9 & $0.5-1.4$ & 0.6 \\
Smoking & 0.6 & $0.21-1.7$ & 0.3 \\
PHQ-9 & 0.96 & $1.01-1.03$ & 0.02 \\
Health care provider recommendation & 2.67 & $1.37-5.44$ & 0.0036 \\
Education level & 1.2 & $1.05-2.62$ & 0.04 \\
Charlson category 2 & 0.80 & $0.42-1.54$ & 0.5 \\
Charlson category 3 & 0.47 & $0.25-0.85$ & 0.01 \\
Charlson category 4 & 0.84 & $0.46-1.57$ & 0.59 \\
MSLs screen & 0.97 & $0.57-1.66$ & 0.9
\end{tabular}

Univariate analysis.

TABLE 4 | Predictors of CR participation.

\begin{tabular}{lccccc}
\hline Parameter & Estimate & $\begin{array}{c}\text { Standard } \\
\text { error }\end{array}$ & $\begin{array}{c}\text { Odds } \\
\text { ratio }\end{array}$ & $\begin{array}{c}\text { 95\% Cl } \\
\text { lower-upper }\end{array}$ & P-value \\
\hline Age & -0.03 & 0.014 & 0.96 & $0.94-0.99$ & 0.005 \\
Male & -0.14 & 0.31 & 0.87 & $0.47-1.60$ & 0.651 \\
Smoking & 0.18 & 0.62 & 1.20 & $0.35-4.06$ & 0.771 \\
PHQ-9 & -0.07 & 0.031 & 0.93 & $0.87-0.99$ & 0.016 \\
Health care provider & 1.28 & 0.43 & 3.62 & $1.55-8.47$ & 0.002 \\
recommendation & & & & & \\
Education level & 0.008 & 0.04 & 1.01 & $0.93-1.10$ & 0.842 \\
Charlson category 2 & -0.51 & 0.33 & 0.60 & $0.32-1.13$ & 0.116 \\
Charlson category 3 & -0.50 & 0.41 & 0.61 & $0.27-1.35$ & 0.221 \\
Charlson category 4 & 0.70 & 0.47 & 2.01 & $0.81-5.02$ & 0.133 \\
MSLs screen & -0.02 & 0.0536 & 0.983 & $0.885-1.092$ & 0.750 \\
\hline
\end{tabular}

Multivariate analysis.

\section{Predictors of CR Attendance}

Data on the number of CR sessions attended per patient were available in the 79 patients who lived in the Rochester, Minnesota area and who attended the Mayo Clinic CR Program, while session attendance was not available on 111 patients who were referred to other CR centers outside of the Rochester area. Among the patients who enrolled in the Mayo Clinic CR program, a lower pain score with activity was associated with a higher number of sessions patients attended $(\mathrm{OR}=1.20,95 \%$, CI: $1.05-1.50, p=0.02026)$. Presence of pain over 1 month or the inability to do exercise because of pain was associated with a lower $\mathrm{CR}$ attendance $(\mathrm{OR}=0.18,95 \% \mathrm{CI}$ : 0.04-0.64; $\mathrm{OR}=0.25$, 95\% CI: 0.09-0.63). Of interest, balance problems were more frequently reported among participants who attended more CR sessions (OR $=3.02,95 \% \mathrm{CI}: 0.12-0.87)$. However, we found that when compared to those without MSLs, the presence of MSLs was associated with lower CR participation $(\mathrm{OR}=0.80,95 \%, \mathrm{CI}$ : $0.65-0.97, p=0.0252)$.

\section{DISCUSSION}

While MSLs were commonly present in our study cohort (82\%), they were not associated with lower CR enrollment, even after taking into consideration the number and severity of MSLs that were reportedly present. Factors that were predictive of CR enrollment included a recommendation by a health care provider for the patient to participate in CR, younger age, and lower depressive symptoms (i.e., lower PHQ-9 score). While CR enrollment rate was 54\%, the likelihood of CR enrollment decreased in stepwise fashion with older age $(p=0.005)$ and higher PHQ 9 score, similarly in men and women $(p=$ 0.69). An individual receiving a strong health care provider's recommendation to attend CR was 4 times as likely to enroll in $\mathrm{CR}$ compared to individuals who did not receive such a recommendation. Overall, we found that MSLs were not associated with lower enrollment in a CR program (Table 4), but they were associated with lower CR session attendance.

These findings are important for several reasons. First, MSLs are common in individuals with cardiovascular disease, suggesting the need for CR programs and other health care providers to screen for and appropriately address the MSLs that are present in their patients. While we did not find MSLs to be a barrier to CR enrollment, we did find that MSLs are associated with lower attendance at CR sessions. Furthermore, MSLs have been previously reported to occur during CR or may be exacerbated during CR $(9,15)$, which might help explain why MSLs are associated with lower attendance at CR sessions. Close collaboration between CR and physical medicine and rehabilitation professionals appears to be warranted for patients with MSLs who participate in CR. The use of personalized exercise prescriptions in such patients could potentially help them improve functional capacity during CR9 (16-21), as well as $\mathrm{CR}$ attendance.

Another reason our findings are important is because they reinforce previous reports that have found a high prevalence and accelerated increase of incidence (22) of comorbidities (two or more chronic health conditions) in individuals with cardiovascular disease (CVD), particularly with regards to the co-existence of musculoskeletal conditions $(8,9)$. This may be secondary to shared risk factors for both MSLs and CVD, such as obesity and aging of the population (23-25). Our study is similar to previous studies that have also shown a high prevalence of MSLs among CR-eligible patients $(8,9)$. Other studies have also found that comorbidities increase the complexity of care required for patients with $\mathrm{CVD}$, can be an important impediment to patient adherence, functional status, and quality of life $(23,26-$ 28 ), and are associated with higher healthcare resource utilization $(29)^{1}$. Care coordination between CR professionals and others involved in the care of CR patients is crucial in patients with comorbid conditions $(26,28,30)$, so that those conditions can be identified and managed effectively, reducing the potential for fragmentation of care which can result in the care of patients with multiple, complex comorbidities.

Finally, our findings are important because they help clarify whether or not MSLs serve as a barrier to CR enrollment, an issue that is both misunderstood and understudied (4, 7, 31-35). We found that while MSLs are common and symptomatic in CR patients, they are not associated with lower CR enrollment, even

\footnotetext{
${ }^{1}$ http://www.cdc.gov/chronicdisease/resources/publications/aag/arthritis.htm
} 
when the number and severity of MSLs are considered. However, we did find that MSLs are associated with lower CR adherence, suggesting that the careful assessment and management of MSLs are important in optimizing the potential cardiovascular benefits of CR in participating patients with MSLs.

\section{Study Limitations}

Our study is limited by the fact that our data are from one center in one geographic area of the mid-western United States with a largely white population. Thus, our findings may not be generalizable to other centers and other populations. In addition, the high prevalence of MSLs may limit our ability to assess the true impact of MSLs on CR enrollment. However, we found no association between MSLs and CR enrollment even when restricting our definition of MSLs to a smaller group of CR patients with the highest number and severity of MSLs. Our data are based on self-reported surveys, which is a potential limitation to our study. The MSL screening tool used, however, was found to have high test-retest validity, which adds support for the use of the self-reported tool in identifying CR-eligible patients with MSLs. The response rate to our survey was moderate $37 \%$ of invited participants), which may have resulted in a sampling bias that could have led to patients with MSLs being more likely to complete and return the survey. However, we sought to overcome this possible bias by considering in our analyses the number and severity of reported MSLs. We found that in all analyses, MSLs were not associated with CR enrollment. Finally, our analyses regarding attendance at $\mathrm{CR}$ sessions were limited data from patients in our cohort who attended CR at the Mayo Clinic and did not include data from patients from other regions of the country who received their initial cardiovascular care at the Mayo Clinic but were subsequently referred to a CR program in other regions of the country, near where they lived.

\section{CONCLUSION}

We found that MSLs, while common and significantly symptomatic in our cohort of CR-eligible patients, were not associated with lower CR enrollment, but were associated with lower CR attendance. MSLs are an important and common comorbidity in CR patients, requiring close collaboration and care coordination between CR staff and physical medicine and

\section{REFERENCES}

1. Anderson L, Oldridge N, Thompson DR, Zwisler AD, Rees K, Martin $\mathrm{N}$, et al. Exercise-based cardiac rehabilitation for coronary heart disease: cochrane systematic review and meta-analysis. J Am Coll Cardiol. (2016) 67:1-12. doi: $10.1016 /$ j.jacc.2015.10.044

2. Wenger NK. Current status of cardiac rehabilitation. J Am Coll Cardiol. (2008) 51:1619-31. doi: 10.1016/j.jacc.2008.01.030

3. Dunlay SM, Pack QR, Thomas RJ, Killian JM, Roger VL. Participation in cardiac rehabilitation, readmissions, and death after acute myocardial infarction. Am J Med. (2014) 127:538-46. doi: 10.1016/j.amjmed.2014.02.008

4. Balady GJ, Ades PA, Bittner VA, Franklin BA, Gordon NF, Thomas RJ, et al. Referral, enrollment, and delivery of cardiac rehabilitation/secondary prevention programs at clinical centers and beyond: a presidential advisory rehabilitation professionals to optimize CR care and outcomes in patients with MSLs (36). Additional research is warranted to identify the most effective management strategies for this common and important group of CR patients.

\section{DATA AVAILABILITY STATEMENT}

The original contributions presented in the study are included in the article/Supplementary Materials, further inquiries can be directed to the corresponding author/s.

\section{ETHICS STATEMENT}

The studies involving human participants were reviewed and approved by Mayo Clinic Institutional Review Board. The patients/participants provided their written informed consent to participate in this study.

\section{AUTHOR CONTRIBUTIONS}

MS, JM-I, CP-T, SS, KG, KV, KS, and RT: conceptualization, writing-review, and editing. JM-I, SS, and KG: formal analysis. CP-T, SS KG, KV, KS, and RT: data curation. MS: writingoriginal draft preparation. RT: supervision. All authors have read and agreed to the published version of the manuscript, gave final approval, and agree to be accountable for all aspects of work ensuring integrity and accuracy.

\section{FUNDING}

Funding for this project was made available through the Small Grants Program, Cardiovascular Department, Mayo Clinic, Rochester, MN, United States. This work was supported in part by the European Regional Development Fund-Project FNUSAICRC (No. Z.1.05/1.1.00/02.0123).

\section{SUPPLEMENTARY MATERIAL}

The Supplementary Material for this article can be found online at: https://www.frontiersin.org/articles/10.3389/fcvm. 2021.688483/full\#supplementary-material from the American Heart Association. Circulation. (2011) 124:295160. doi: 10.1161/CIR.0b013e31823b21e2

5. Mosca L, Benjamin EJ, Berra K, Bezanson JL, Dolor RJ, Lloyd-Jones DM, et al. Effectiveness-based guidelines for the prevention of cardiovascular disease in women-2011 update: a guideline from the american heart association. Circulation. (2011) 123:1243-62. doi: 10.1161/CIR.0b013e31820faaf8

6. Grace SL, Gravely-Witte S, Kayaniyil S, Brual J, Suskin N, Stewart DE. A multisite examination of sex differences in cardiac rehabilitation barriers by participation status. J Womens Health (Larchmt). (2009) 18:20916. doi: 10.1089/jwh.2007.0753

7. Marzolini S, Brooks D, Oh PI. Sex differences in completion of a 12-month cardiac rehabilitation programme: an analysis of 5922 women and men. Eur J Cardiovasc Prev Rehabil. (2008) 15:698-703. doi: 10.1097/HJR.0b013e32830c1ce3 
8. Goel K, Shen J, Wolter AD, Beck KM, Leth SE, Thomas RJ, et al. Prevalence of musculoskeletal and balance disorders in patients enrolled in phase II cardiac rehabilitation. J Cardiopulm Rehabil Prev. (2010) 30:2359. doi: 10.1097/HCR.0b013e3181e17387

9. Khan M, Neuhof A, Tsai S, Powell S, Silaj E, MacNeill H, Oh P, et al. Examination of cardiac rehabilitation participants referred to a musculoskeletal clinic. J Cardiopulm Rehabil Prev. (2014) 34:3437. doi: 10.1097/HCR.0000000000000040

10. Hoy DG, Smith E, Cross M, Sanchez-Riera L, Blyth FM, Buchbinder R, et al. Reflecting on the global burden of musculoskeletal conditions: lessons learnt from the global burden of disease 2010 study and the next steps forward. Ann Rheum Dis. (2015) 74:4-7. doi: 10.1136/annrheumdis-2014-205393

11. Bansilal S, Castellano JM and Fuster V. Global burden of CVD: focus on secondary prevention of cardiovascular disease. Int J Cardiol. (2015) 201(Suppl. 1):S1-7. doi: 10.1016/S0167-5273(15)31026-3

12. Mendis S, Chestnov O. The global burden of cardiovascular diseases: a challenge to improve. Curr Cardiol Rep. (2014) 16:486. doi: 10.1007/s11886-014-0486-3

13. Briggs AM, Cross MJ, Hoy DG, Sànchez-Riera L, Blyth FM, Woolf $\mathrm{AD}$, et al. Musculoskeletal health conditions represent a global threat to healthy aging: a report for the 2015 world health organization world report on ageing and health. Gerontologist. (2016) 56(Suppl. 2):S24355. doi: 10.1093/geront/gnw002

14. Kroenke K, Spitzer RL, Williams JB. The PHQ-9: validity of a brief depression severity measure. J Gen Intern Med. (2001) 16:606-13. doi: 10.1046/j.1525-1497.2001.016009606.x

15. Hootman JM, Macera CA, Ainsworth BE, Martin M, Addy CL, Blair SN. Association among physical activity level, cardiorespiratory fitness, and risk of musculoskeletal injury. Am J Epidemiol. (2001) 154:2518. doi: 10.1093/aje/154.3.251

16. Bennell KL, Dobson F, Hinman RS. Exercise in osteoarthritis: moving from prescription to adherence. Best Pract Res Clin Rheumatol. (2014) 28:93117. doi: 10.1016/j.berh.2014.01.009

17. Jordan JL, Holden MA, Mason EE, Foster NE. Interventions to improve adherence to exercise for chronic musculoskeletal pain in adults. Cochrane Database Syst Rev. (2010) 2010:CD005956. doi: 10.1002/14651858.CD005956.pub2

18. Jordan KM, Arden NK, Doherty M, Bannwarth B, Bijlsma JW, Dieppe P, et al. EULAR Recommendations 2003: an evidence based approach to the management of knee osteoarthritis: report of a task force of the standing committee for international clinical studies including therapeutic trials (ESCISIT). Ann Rheum Dis. (2003) 62:1145-55. doi: 10.1136/ard.2003.011742

19. Zhang W, Nuki G, Moskowitz RW, Abramson S, Altman RD, Arden NK, et al. OARSI recommendations for the management of hip and knee osteoarthritis: part III: Changes in evidence following systematic cumulative update of research published through January 2009. Osteoarthritis Cartilage. (2010) 18:476-99. doi: 10.1016/j.joca.2010.01.013

20. Zhang W, Moskowitz RW, Nuki G, Abramson S, Altman RD, Arden N, et al. OARSI recommendations for the management of hip and knee osteoarthritis, Part II: OARSI evidence-based, expert consensus guidelines. Osteoarthritis Cartilage. (2008) 16:137-62. doi: 10.1016/j.joca.2007.12.013

21. Zhang W, Moskowitz RW, Nuki G, Abramson S, Altman RD, Arden N, et al. OARSI recommendations for the management of hip and knee osteoarthritis, part I: critical appraisal of existing treatment guidelines and systematic review of current research evidence. Osteoarthritis Cartilage. (2007) 15:9811000. doi: 10.1016/j.joca.2007.06.014

22. Fabbri E, Zoli M, Gonzalez-Freire M, Salive ME, Studenski SA, Ferrucci L. Aging and multimorbidity: new tasks, priorities, and frontiers for integrated gerontological and clinical research. J Am Med Dir Assoc. (2015) 16:6407. doi: 10.1016/j.jamda.2015.03.013
23. Marzolini S, Candelaria H, Oh P. Prevalence and impact of musculoskeletal comorbidities in cardiac rehabilitation. J Cardiopulm Rehabil Prev. (2010) 30:391-400. doi: 10.1097/HCR.0b013e3181e174ac

24. Peltonen M, Lindroos AK, Torgerson JS. Musculoskeletal pain in the obese: a comparison with a general population and long-term changes after conventional and surgical obesity treatment. Pain. (2003) 104:54957. doi: 10.1016/S0304-3959(03)00091-5

25. Siebens HC. Musculoskeletal problems as comorbidities. Am J Phys Med Rehabil. (2007) 86:S69-78. doi: 10.1097/PHM.0b013e31802ba581

26. Bahler C, Huber CA, Brungger B, Reich O. Multimorbidity, health care utilization and costs in an elderly community-dwelling population: a claims data based observational study. BMC Health Serv Res. (2015) 15:23. doi: 10.1186/s12913-015-0698-2

27. Lugtenberg M, Burgers JS, Clancy C, Westert GP, Schneider EC. Current guidelines have limited applicability to patients with comorbid conditions: a systematic analysis of evidence-based guidelines. PLOS ONE. (2011) 6:e25987. doi: 10.1371/journal.pone.0025987

28. Dunlay SM, Chamberlain AM. Multimorbidity in older patients with cardiovascular disease. Curr Cardiovasc Risk Rep. (2016) 10:3. doi: 10.1007/s12170-016-0491-8

29. Trogdon JG, Murphy LB, Khavjou OA, Li R, Maylahn CM, Tangka FK, et al. Costs of Chronic Diseases at the State Level: The Chronic Disease Cost Calculator. Prev Chronic Dis. (2015) 12: E140. doi: 10.5888/pcd12.150131

30. Arnett DK, Goodman RA, Halperin JL, Anderson JL, Parekh AK, Zoghbi WA. AHA/ACC/HHS strategies to enhance application of clinical practice guidelines in patients with cardiovascular disease and comorbid conditions: from the American Heart Association, American College of Cardiology, and US Department of Health and Human Services. Circulation. (2014) 130:16627. doi: 10.1161/CIR.0000000000000128

31. Ades PA, Waldmann ML, McCann WJ, Weaver SO. Predictors of cardiac rehabilitation participation in older coronary patients. Arch Intern Med. (1992) 152:1033-5. doi: 10.1001/archinte.1992.004001701 13021

32. Tavella R, Beltrame JF. Cardiac rehabilitation may not provide a quality of life benefit in coronary artery disease patients. BMC Health Serv Res. (2012) 12:1-9. doi: 10.1186/1472-6963-12-406

33. Moore SM, Dolansky MA, Ruland CM, Pashkow FJ, Blackburn GG. Predictors of women's exercise maintenance after cardiac rehabilitation. J Cardiopulm Rehabil. (2003) 23:40-9. doi: 10.1097/00008483-200301000-00008

34. Jurkiewicz MT, Marzolini S, Oh P. Adherence to a home-based exercise program for individuals after stroke. Top Stroke Rehabil. (2011) 18:27784. doi: 10.1310/tsr1803-277

35. CDC. Arthritis as a potential barrier to physical activity among adults with heart disease-united states, 2005 and 2007. MMWR. (2009) 58:165-9.

36. Papathanasiou J, Troev T, Ferreira AS, Tsekoura D, Elkova H, Kyriopoulos E, et al. Advanced role and field of competence of the physical and rehabilitation medicine specialist in contemporary cardiac rehabilitation. Hellenic J Cardiol. (2016) 57:16-22. doi: 10.1016/S1109-9666(16)30013-6

Conflict of Interest: The authors declare that the research was conducted in the absence of any commercial or financial relationships that could be construed as a potential conflict of interest.

Copyright (C) 2021 Supervia, Medina-Inojosa, Pérez-Terzic, Sharma, Goel, Vickers Douglas, Salz and Thomas. This is an open-access article distributed under the terms of the Creative Commons Attribution License (CC BY). The use, distribution or reproduction in other forums is permitted, provided the original author(s) and the copyright owner(s) are credited and that the original publication in this journal is cited, in accordance with accepted academic practice. No use, distribution or reproduction is permitted which does not comply with these terms. 